\title{
Vulval carcinoma at the site of recent Bartholin gland excision: a rare case report
}

\author{
B. Kalpana ${ }^{1 *}$, S. G. Balamurugan ${ }^{2}$, Soumya Ranjan Panda ${ }^{3}$
}

\author{
${ }^{1}$ Department of Reproductive Medicine, Guru Hospital, Madurai, Tamil Nadu, India \\ ${ }^{2}$ Department of Surgical Oncology, Guru Hospital, Madurai, Tamil Nadu, India \\ ${ }^{3}$ Department of Obstetrics and Gynecology, AIIMS, Mangalagiri, Andhra Pradesh, India
}

Received: 12 February 2020

Accepted: 04 March 2020

\section{*Correspondence:}

Dr. B. Kalpana,

E-mail: balamurugan_kalpana@rediffmail.com

Copyright: (c) the author(s), publisher and licensee Medip Academy. This is an open-access article distributed under the terms of the Creative Commons Attribution Non-Commercial License, which permits unrestricted non-commercial use, distribution, and reproduction in any medium, provided the original work is properly cited.

\begin{abstract}
Around 2-7\% of all vulvar cancers are represented by primary carcinomas of Bartholin gland. Here we are presenting such a rare case of carcinoma of Bartholin gland. 45/F P2L2 presented in our OPD with non-healing lesion in vulva for 2 months. She had history of Bartholin's cyst excision (elsewhere), 2 months back (the exact time since when she is having the non-healing lesion in vulva). Diagnostic biopsy revealed it to be vulval squamous cell carcinoma. She was given two cycles of Neo adjuvant chemotherapy (Inj. Paclitaxel and Carboplatin). In view of better response to the treatment patient was planned for surgery. Patient underwent wide local excision with bilateral inguinofemoral lymphadenectomy. Although the majority of vulvar lesions are benign, especially in women younger than 50 years of age, any solid mass should be carefully evaluated for malignancy. Preferably biopsy of Bartholin gland should be considered if the patient is more than 40 years of age and should be mandatory in a menopausal woman.
\end{abstract}

Keywords: Bartholin gland, Vulvectomy, Vulval carcinoma

\section{INTRODUCTION}

Around $2-7 \%$ of all vulvar cancers are represented by primary carcinomas of Bartholin gland. ${ }^{1,2}$ These can be squamous, papillary, or adenocarcinomas depending on the location of origin. Bartholin gland tumors are more common in advanced age group women and the median age of diagnosis is 57 years. The rarity of this carcinoma lies in its aggressive nature with protracted clinical symptoms and a tendency for local recurrence despite adequate surgical excision with or without adjuvant radiotherapy. Here we are presenting such a rare case of carcinoma of Bartholin gland.

\section{CASE REPORT}

A 45/F P2L2 presented in OPD with non-healing lesion in vulva for 2 months. She had history of Bartholin's cyst excision (elsewhere), 2 months back (the exact time since when she is having the non-healing lesion in vulva). She was a known case of DM. Her general and systemic examination findings were within normal limit. On local examination there was an ulcerative lesion of size $3 \times 2 \mathrm{~cm}$ involving the right labia majora. Diagnostic biopsy revealed it to be vulval squamous cell carcinoma (Figure $1)$.

CT scan reported as splenomegaly with hypodense lesion, complex left adnexal cyst $3 \times 3 \mathrm{~cm}$ whereas PET CT reported as Irregular ulcerated mass lesion measuring $5.1 \times 2.8 \times 3.3 \mathrm{~cm}$ involving vulva predominant on the right side extending into the lower part of vagina superiorly. Right external, right obturator, right internal iliac, right inguinal lymph nodes involvement was seen. Hence the case was diagnosed as locally advanced vulva carcinoma. The plan of treatment was neo adjuvant chemotherapy 
followed by surgery. She was given two cycles of neo adjuvant chemotherapy (Inj. Paclitaxel and Carboplatin). In view of better response to the treatment patient was planned for surgery. Patient underwent wide local excision with bilateral inguinofemoral lymphadenectomy.

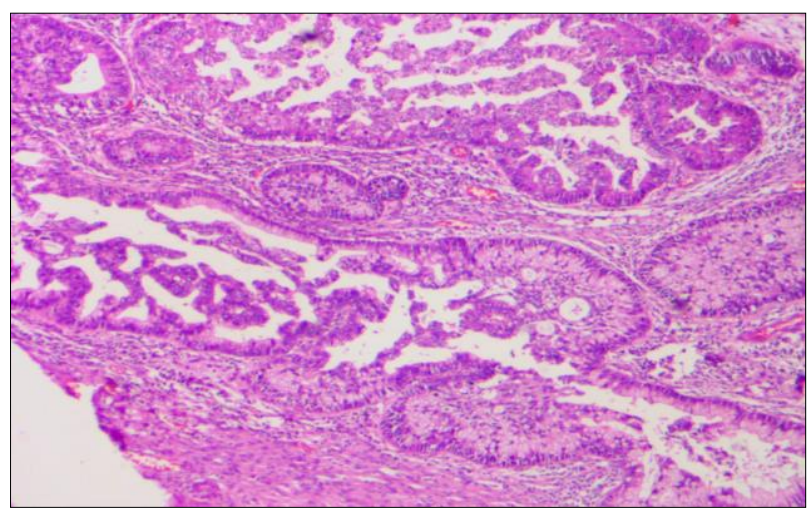

Figure 1: Biopsy of the lesion confirming it as vulval squamous cell carcinoma.

\section{Vulvectomy}

Under epidural, under SA, under ASP lithotomy position, parts painted and draped. Vulva lesion excised into with 2 $\mathrm{cm}$ clearance and defect closed with 2-0 vicryl with $16 \mathrm{f}$ drain kept and fixed. Right inguinal region $\mathrm{S}$ shaped incision made and flap raised $>$ inguinal dissection done with laterally medial border of superiorly inguinal ligament, inferior - apex of femoral triangle. Medially pubic tubercle excised into iliac node dissection done. Iliac vessel skeletonized. Hemostasis secured. Drain kept and fixed. Wound closed in layers. dressing done. Postoperative histopathology reported as well differentiated Infiltrating squamous cell carcinoma with positive Inguinal lymph nodes. AJCC TNM staging was - pT1b pN2b.

\section{DISCUSSION}

The most common presenting complain of these patients is a painless vulvar mass. ${ }^{3,4}$ Bartholin gland enlargement in a postmenopausal woman should raise suspicions of malignancy because benign inflammatory disease typically does not occur in this age group. A biopsy should be performed for any abnormal growth of the Bartholin gland if the patient is older than 40 years. The differential diagnosis for a Bartholin gland tumor most commonly includes cysts and abscesses, which occur in $2 \%$ of women, and other vulvovaginal disorders, such as vulvar carcinoma, acrochordons, hidradenomas, other dermatoses, and condyloma acuminate. The Bartholin gland is composed of columnar epithelium, and the ducts are lined by stratified squamous epithelium, which changes to transitional cell epithelium toward the terminal ducts. Squamous cell carcinoma is the only lesion of the Bartholin gland linked to human papillomavirus. Metastases are common as a result of the copious supply of vascular and lymphatic networks in the area. Approximately 50\% of Bartholin's gland tumors are squamous cell carcinomas. Prognosis in vulvar tumors is related to regional lymph node involvement, size, and location.

A phase II study examined the use of preoperative chemoradiotherapy to avert the need for more radical surgery. The authors came to a conclusion that preoperative chemoradiotherapy in advanced squamous cell carcinoma of the vulva is feasible and may decrease the need for more radical surgery. ${ }^{5}$ In another study, Han et al, concluded that concurrent chemoradiotherapy as primary treatment for locally advanced vulvar cancer decreases local relapse rate and improves disease-specific and overall survival versus radiotherapy alone. ${ }^{6}$

In this case the biopsy of the Bartholin gland was not done assuming that it was a benign cyst. However later it was found out to be malignant. Based on this case report can conclude biopsy of Bartholin gland should be considered in patients those are more than 40 years of age and should be mandatory in a menopausal woman.

\section{CONCLUSION}

Although the majority of vulvar lesions are benign, especially in women younger than 50 years of age, any solid mass should be carefully evaluated for malignancy. The authors acknowledge its rarity but suggest that a differential diagnosis which includes a suspicion of its role in the aetiology of Bartholin gland disorders may well help the optimization of appropriate patient care. Preferably biopsy of Bartholin gland should be considered if the patient is more than 40 years of age and should be mandatory in a menopausal woman. More research and case reports on this rare cancer are needed in order to further comprehend and manage the disease.

\section{Funding: No funding sources Conflict of interest: None declared Ethical approval: Not required}

\section{REFERENCES}

1. Bernstein SG, Voet RL, Lifshitz S, Buchsbaum HJ. Adenoid cystic carcinoma of Bartholin's gland. Case report and review of the literature. Am J Obstet Gynecol. 1983;147(4):385-90.

2. Nasu K, Kawano Y, Takai N, Kashima K, Miyakawa I. Adenoid cystic carcinoma of Bartholin's gland. Case report with review of the literature. Gynecol Obstet Investig. 2005;59(1):54-8.

3. Elkas JC, Berek JS. Clinical manifestations, diagnosis, pathology, and staging of vulvar cancer. Up to date patient information. Up to date, Inc.; c2007. Available at: http://uptodate.com. Accessed on $10^{\text {th }}$ January 2020.

4. Chen KT. Disorders of Bartholin's gland. UpToDate Patient Information. Up to date, Inc.; c2007. 
Available at: http://uptodate.com. Accessed on $10^{\text {th }}$ January 2020.

5. Moore DH, Thomas GM, Montana GS, Saxer A, Gallup DG, Olt G. Preoperative chemoradiation for advanced vulvar cancer: a phase II study of the gynecologic oncology group. Int J Radiat Oncol Biol Phys. 1998;42:79-85.

6. Han SC, Kim DH, Higgins SA, Carcangiu ML, Kacinski BM. Chemoradiation as primary or adjuvant treatment for locally advanced carcinoma of the vulva. Int $\mathbf{J}$ Radiat Oncol Biol Phys. 2000;47:1235-44.

Cite this article as: Kalpana B, Balamurugan SG, Panda SR. Vulval carcinoma at the site of recent Bartholin gland excision: a rare case report. Int J Reprod Contracept Obstet Gynecol 2020;9:2148-50. 